\title{
1 Stoichiometric regulation of phytoplankton toxins
}

2 Dedmer B. Van de Waal ${ }^{1, *}$, Val H. Smith ${ }^{2}$, Steven A.J. Declerck ${ }^{1}$, Eva C.M. Stam ${ }^{1}$ \& James J.

3 Elser $^{3}$

4

$5 \quad{ }^{1}$ Department of Aquatic Ecology, Netherlands Institute of Ecology (NIOO-KNAW), Post Office

6 Box 50, $6700 \mathrm{AB}$ Wageningen, The Netherlands.

$7 \quad{ }^{2}$ Department of Ecology and Evolutionary Biology, University of Kansas, Lawrence, Kansas 866045, USA.

$9 \quad{ }^{3}$ School of Life Sciences, Arizona State University, Tempe, AZ 85287-4501, USA.

$10 *$ *Correspondence: Dedmer B. Van de Waal. E-mail: d.vandewaal@nioo.knaw.nl; Phone: +31

11317473 553; Fax: +31317473675 .

12
Running title: Stoichiometric regulation of toxins

Type of article: Letter; Words in abstract: 159; Words in manuscript: 3343; Number of references: 50; Number of figures and tables: 5; Email addresses: Dedmer B. Van de Waal, d.vandewaal@nioo.knaw.nl; Val H. Smith, vsmith@ku.edu; Steven A.J. Declerck, s.declerck@nioo.knaw.nl; Eva C. Stam, ecm.stam@gmail.com; James J. Elser, j.elser@asu.edu.

Statement of authorship: D.B.v.d.W. and E.C.M.S. recovered the data. All authors analyzed the data and discussed the results. D.B.v.d.W. wrote the first draft of the manuscript, and all authors contributed substantially to revisions. 


\section{Abstract}

Ecological Stoichiometry theory predicts that the production, elemental structure, and cellular content of biomolecules should depend upon the relative availability of resources and the elemental composition of their producer organism. We review the extent to which carbon- and nitrogen-rich phytoplankton toxins are regulated by nutrient limitation and cellular stoichiometry. Consistent with theory, we show that nitrogen limitation causes a reduction in the cellular quota of nitrogen-rich toxins, while phosphorus limitation causes an increase in the most nitrogen-rich paralytic shellfish poisoning toxin. In addition, we show that the cellular content of nitrogen-rich toxins increases with increasing cellular N:P ratios. Also consistent with theory, limitation by either nitrogen or phosphorus promotes the cellular quota, or toxicity, of the investigated carbon-rich toxins. These observed relationships may assist in predicting and managing toxin-producing phytoplankton blooms. Such a stoichiometric regulation of toxins is likely not restricted to phytoplankton, and may well apply to carbon- and nitrogen-rich secondary metabolites produced by bacteria, fungi, and plants.

Key words: Ecological Stoichiometry, harmful cyanobacteria, Harmful Algal Blooms, natural toxins, nutrient limitation, secondary metabolites. 


\section{Introduction}

It is well-established that the elemental composition of both prokaryotic and eukaryotic cells strongly depends upon the supplies of chemical elements, such as the key nutrients nitrogen (N) and phosphorus (P) (Sterner \& Elser 2002; Klausmeier et al. 2004). Primary producers use light energy to convert $\mathrm{CO}_{2}$ and nutrients into an enormous variety of organic compounds, including fatty acids, amino acids, and nucleic acids. These three key groups of biomolecules differ significantly in their elemental composition, notably in their relative carbon (C), N, and P contents. Similarly, there are major differences in the C:N:P stoichiometry of secondary cellular metabolites, which are known to serve as signaling molecules as well as deterrents against pathogens and herbivores (Keller \& Surette 2006; Iason et al. 2013). Some of the secondary metabolites produced by planktonic aquatic primary producers (unicellular and colonial cyanobacteria and eukaryotic algae, collectively termed "phytoplankton" hereafter) are toxic to invertebrates, fish, birds, and mammals. Blooms of such toxic phytoplankton are of increasing global concern because their appearance and proliferation are driven by high anthropogenic loadings of $\mathrm{N}$ and $\mathrm{P}$ to surface waters (eutrophication) (Anderson et al. 2002; Smith 2003). Thus, there is a strong need to gain a better understanding of how the absolute and relative supplies of key nutrients affect the production of toxic compounds by bloom-forming phytoplankton.

Toxins produced by phytoplankton are stoichiometrically diverse, ranging from N-rich alkaloids to C-based polyketides (Table 1). Previous studies involving particular phytoplankton taxa have demonstrated that the production and cellular contents (internal cell "quota") of C- and N-rich toxins respond strongly to the relative availability of nutrients (Granéli et al. 1998; Sivonen \& Jones 1999; Granéli \& Flynn 2006; Van de Waal et al. 2009). Here, we present the first quantitative analysis of the regulation of phytoplankton toxins by nutrient limitation. We 
analyzed >500 published studies and compiled a total of 180 datasets, covering 31 phytoplankton species representing 19 different genera (Fig. S1; Table S1). Using these data, we analyzed the toxin cell quotas or toxicities of phytoplankton cells grown under either $\mathrm{N}$ - or P-limitation, and we compared these responses with cells grown in nutrient-sufficient controls. Based on stoichiometric theory (Sterner \& Elser 2002) and current understanding of phytoplankton physiology, we predicted that production of C-rich toxic compounds would be elevated under both $\mathrm{N}$ - and P-limitation because, under such conditions, cellular $\mathrm{C}$ is by definition in excess and can accumulate in secondary pools. Following similar reasoning, we also predicted that production of $\mathrm{N}$-rich toxins would be inhibited under $\mathrm{N}$-limitation (because $\mathrm{N}$ is shunted into intracellular pools to support active growth), but amplified under P-limitation (because $\mathrm{N}$ is in excess and accumulates in secondary intracellular pools).

\section{Material and Methods}

Data was obtained by ISI Web of Science searches with the terms: ("phytoplankton" or "cyanobacteri*" or "dinoflagellate*") and "*toxin*" and ("nutrient*" or "nitr*" or "phosph*") (Fig. S1; Tables S1 and S2). Estimates of toxin quota or toxicity of phytoplankton grown under low $\mathrm{N}$ and/or low $\mathrm{P}$ were recovered from the stationary growth phase of batch culture experiments, and from steady state conditions of continuous cultures. Toxin quotas or toxicities of cells grown under nutrient-sufficient conditions, or at maximum growth rates during the exponential phase, served as controls. Studies reporting earlier published data were not included. We made a distinction between $\mathrm{N}$-rich and C-rich toxins based on elemental composition. Toxins with a molar $\mathrm{C}: \mathrm{N}$ ratio <6.6 (i.e. less than the Redfield ratio) were considered "N-rich", whereas toxins with a higher molar $\mathrm{C}: \mathrm{N}$ ratio were considered "C-rich" (Table 1). For each study we took 
toxin quotas or toxicities and calculated the average response ratio (RR) by normalizing toxin quotas or toxicities from the low $\mathrm{N}$ and low $\mathrm{P}$ conditions to the control. Furthermore, we derived cellular N:P ratios expressed as molar ratios.

Toxins were found to be represented by varying numbers of studies (Fig. S1). Some toxins were produced by multiple species, and these toxins were represented by different numbers of species (Fig. S1). To correct for biases that may result from such unbalanced and nested data structure, we worked with weighted means and variances. First, we calculated the average response and variance for each toxin that was represented by at least three or more independent studies (i.e. $n>3$ ). In case a toxin was produced by multiple species, and one species was represented by more than two studies, we first calculated the mean of this species and then calculated the average response of the toxin across species. In case multiple species were represented by multiple studies, the weighted average response of a toxin across species could be calculated according to (Borenstein et al. 2009):

$M_{R R, W}=\frac{\sum_{i=1}^{n} M_{R R} W_{i}}{\sum_{i=1}^{n} W_{i}}$

with weight $W_{i}$ being the reciprocal of the variance $V_{t o x}$, $p$, i.e. the variance among studies for each species $i$, calculated as:

$V_{t o x, s p}=\frac{1}{n-1} \sum_{i=1}^{n}\left(R R_{i}-M_{R R}\right)^{2}$

Similarly, the overall weighted average response of toxins across the means of all N- or C-rich toxins was calculated. We assessed the statistical significance of differences between the calculated RRs and their respective controls with a one sample t-test comparing the weighted mean RR with 1 , which represents the absence of a response $(\alpha<0.05)$.

\section{Results}


110 The assembled studies yielded 100 datasets with N-rich toxins (49 with N-limitation and 51 with

111 P-limitation) and 80 datasets with C-rich toxins (37 with N-limitation and 43 with P-limitation;

112 Fig. S1). N-rich toxins predominantly consisted of Paralytic Shellfish Poisoning (PSP) toxins

113 produced by marine dinoflagellates $(n=57)$, followed by microcystins (MCs) produced by

114 freshwater cyanobacteria $(n=34)$. Data on C-rich toxins comprised 12 compounds, groups of

115 compounds, or toxicities associated to C-rich toxins. The C-rich toxins were almost exclusively

116 found in marine ecosystems and consisted of various toxins produced by dinoflagellates

117 (including Diarrhetic Shellfish Poisoning (DSP) toxins, $n=18$, karlotoxins (KMTX), $n=11$, and

118 Neurotoxic Shellfish Poisoning (NSP) toxins, $n=10$ ), diatoms (Amnesic Shellfish Poisoning

119 (ASP) toxins, $n=9$ ), and prymnesiophytes (hemolytic activity (HA), $n=12$ ). Various toxins were

120 only represented by a limited number of studies $(n<3)$ and were therefore excluded from our

121 analyses. For most of the toxins, experiments with $\mathrm{N}$-limitation and P-limitation tended to be

122 equally well-represented (Fig. S1).

The impact of nutrient limitation on toxin quota or toxicity varied greatly and depended

124 strongly on the stoichiometric nature of the toxins. Consistent with theoretical predictions, our

125 analysis revealed that $\mathrm{N}$-rich toxins generally decreased upon $\mathrm{N}$-limitation while $\mathrm{C}$-rich toxins

126 generally increased upon limitation by either N or P (Figs. 1 and 2). More specifically, cellular

127 quota of both N-rich PSP toxins and MCs decreased significantly upon N-limitation, irrespective

128 of the producing taxonomic group. Upon P-limitation, cellular quota of dinoflagellate PSP toxins

129 increased by 32\%, while MCs decreased by 75\% (Fig. 1; Table 2). Relative changes in C-rich

130 toxins were generally larger than the N-rich toxins, particularly under P-limitation, although

131 variances within toxins were also higher. Significant increases in cellular toxin quota ranged 
132 from $99 \%$ in NSP toxins under N-limitation to $215 \%$ in KMTX under P-limitation (Fig. 2; Table $1332)$. typically converge upon the so-called 'Redfield ratio' of N:P=16 (Sterner \& Elser 2002). Indeed, in the control treatments of the experiments we assembled, cellular N:P ratios resembled the

137 Redfield ratio, whereas cellular N:P stoichiometry was almost always lower than Redfield under 138 N-limitation and higher than Redfield under P-limitation (Fig. 3). N-rich toxins showed a 139 positive linear relationship with cellular N:P ratios. The response ratios of the N-rich PSP toxins

140

Under balanced, non-limiting growth conditions, molar phytoplankton N:P ratios and MCs decreased below 1 at $\mathrm{N}: \mathrm{P}$ ratios below the Redfield ratio, but increased beyond 1 when $\mathrm{N}: \mathrm{P}$ ratios exceeded the Redfield ratio (Fig. 3a). In contrast, the C-rich DSP toxins and HA increased at N:P ratios both below and above the Redfield ratio (Fig. 3b).

\section{Discussion}

Our results demonstrate that the synthesis of N-rich and C-rich toxins is regulated by the relative availabilities of $\mathrm{N}$ and $\mathrm{P}$ (Figs. 1 and 2). Upon N-limitation, cellular quota of the N-rich PSP toxins and microcystins decreased, while upon P-limitation, cellular quota of the most N-rich PSP toxins increased. Cellular quota of microcystin, however, showed a strong decrease, and nodularin did not change upon P-limitation (Fig. 1). These contrasting responses to P-limitation may reflect the fact that, unlike eukaryotic algae, cyanobacteria can shunt excess $\mathrm{N}$ into the storage compound cyanophycin (Allen 1984), a process that likely prevents $\mathrm{N}$ from accumulating primarily as microcystin. C-rich toxins generally increased upon limitation by both $\mathrm{N}$ and $\mathrm{P}$ (Fig. 2). Most of the C-rich toxins were produced by eukaryotic algae and are polyketides, whose synthesis is tightly coupled with cellular C acquisition (Staunton \& 
Weissman 2001). Thus, under conditions of nutrient limitation, the relative excess of energy and newly-synthesized organic $\mathrm{C}$ cannot be used for cell growth and instead appears to be shunted into C-rich molecules such as lipids and polyketides, including those that have toxic effects. We also observed a general increase of $\mathrm{N}$-rich toxins with cellular $\mathrm{N}: \mathrm{P}$ ratio (Fig. 3a), while $\mathrm{C}$-rich toxins showed an initial decrease with N:P ratios until reaching the Redfield ratio, after which their content increased (Fig. 4b). These findings are consistent with the 'V-shaped' response to $\mathrm{N}: \mathrm{P}$ ratios that has been reported previously for hemolytic activity associated with C-rich compounds (Granéli \& Flynn 2006; Granéli et al. 2012).

While most of the selected datasets reported cellular toxin quotas, a few $(\sim 6 \%)$ assessed toxicities relative to a standard toxin analogue, for instance as saxitoxin equivalents (Table S1). Changes in these relative toxicities are generally associated with changes in cellular toxin quota, yet may also relate to a shift in the toxin composition (Cembella 1998; Sivonen \& Jones 1999). Because the few selected studies reporting relative toxicities generally showed none, or only minor shifts in toxin composition, we considered the observed changes in relative toxicities to mainly reflect changes in the N-rich toxin quota. All reported hemolytic activities of prymnesiophytes were assessed by bioassays and have been ascribed to various C-rich compounds, such as glycolipids and the polyether prymnesin (Edvardsen \& Imai 2006; Granéli et al. 2012). Although hemolytic activity showed a high average response to nutrient limitation, the variance was also very high (Table 2), which may reflect a higher inherent variability of bioassay data relative to direct chemical measurements of the cellular quota of a specific compound. Nevertheless, our analysis reveals that the response of hemolytic activity by prymnesiophytes towards both $\mathrm{N}$ - and P-limitation is consistent with the general response of Crich toxins, and therefore presumably reflects changes in cellular quotas of a C-rich compound. 
Toxins produced by various harmful phytoplankton taxonomic groups have been shown to exhibit a broad range of potential functions, including grazer deterrence, prey capture, and resource uptake (see also Granéli \& Turner 2006; Glibert \& Burkholder 2011). The question remains whether our results reflect a possible role of toxins in acquiring $\mathrm{N}$ and $\mathrm{P}$, or if the toxin quota merely responds to the relative availability of $\mathrm{N}$ and $\mathrm{C}$ within the cells. Production of $\mathrm{N}-$ rich toxins generally decreased with $\mathrm{N}$-limitation, suggesting a cost rather than a benefit under $\mathrm{N}$-limitation. Cellular contents of N-rich cyanobacterial toxins strongly decreased or remained unaltered upon P-limitation, whereas the quota of N-rich dinoflagellate PSP toxins increased. Crich toxins in dinoflagellates and diatoms, as well as hemolytic activity caused by prymnesiophytes, also increased with P-limitation, and the dinoflagellate karlotoxin and NSP toxins increased significantly with $\mathrm{N}$-limitation. These findings suggest that toxin synthesis may be related to resource acquisition, specifically $\mathrm{C}$-rich toxins for acquiring P. Indeed, C-rich toxins produced by prymnesiophytes seem to be involved in prey capture (Skovgaard et al. 2003; Tillmann 2003). Furthermore, nutrient limitation may stimulate feeding by mixotrophic dinoflagellates and prymnesiophytes (Legrand et al. 2001; Smalley et al. 2003), though it is not clear whether this is related to their toxicity (Stoecker et al. 2006). Thus, whether toxins stimulated by nutrient limitation are indeed involved in resource acquisition and prey capture, or whether they merely respond to a relative excess of non-limiting resources required for their synthesis, needs to be further elucidated.

Our findings illustrate that the extent to which phytoplankton are able to produce toxins, and thereby exploit their putative function, will partially depend on the relative availabilities of $\mathrm{N}$ and $\mathrm{P}$ in the environment. Because $\mathrm{N}$ and $\mathrm{P}$ often limit phytoplankton growth in both freshwater and marine ecosystems (Elser et al. 2007), the cellular production of C-rich toxins 
avoids resource allocation conflicts between population growth and secondary metabolite synthesis. Production of N-rich toxins, however, does decrease with N-limitation, suggesting that $\mathrm{N}$ is allocated to growth rather than secondary metabolites. Growth and the synthesis of biochemicals together will determine the elemental stoichiometry of phytoplankton, which shows distinct differences between taxonomic groups. For instance, dinoflagellates exhibit higher C:N and C:P ratios as compared to prymnesiophytes and diatoms (Quigg et al. 2003), while cyanobacteria have generally higher optimal N:P ratios than diatoms (Hillebrand et al. 2013). Most of the C-rich toxins studied here were indeed produced by dinoflagellates (i.e. 10 out of 12 toxins; Fig. S1), and the reported N-rich toxins were produced by cyanobacteria (i.e. MC, PSP, NOD and CYN) or seem to have a common origin with cyanobacteria (i.e. PSP; Moustafa et al. 2009; Hackett et al. 2013). We did not observe differences in the elemental composition between taxonomic groups, yet our results demonstrate that the cellular quota of the N-rich PSP toxins and microcystins are strongly correlated with N:P stoichiometry, and this relationship is irrespective of the producing taxonomic group, both at the genus as well as at the species level (Fig. 3). To what extent the stoichiometry of a taxonomic group may influence the stoichiometry of the toxins that can be produced remains to be elucidated. Obviously, cellular elemental ratios strongly reflect the intracellular content of major biochemicals such as proteins and nucleic acids (Sterner \& Elser 2002). Here, we show that they may also determine, at least partially, the stoichiometry of secondary metabolites that can be synthesized by the cell.

The strong association of phytoplankton toxins with N:P stoichiometry has important implications for interpreting and predicting the responses of phytoplankton-associated toxins to human-induced changes in the magnitude and ratios of $\mathrm{N}$ and $\mathrm{P}$ supplies to surface waters. One of the clearest and most predictable responses of both freshwater and marine ecosystems to 
224 increased nutrient loading is the profound stimulation of phytoplankton biomass, often by orders

225 of magnitude (Smith 2003; Dolman et al. 2012; Orihel et al. 2012). Total toxin concentrations in

226 natural waters will therefore tend to increase with eutrophication-driven increases in total

227 phytoplankton biomass, but the magnitude of this response will be amplified if nutrient

228 enrichment also selects for dominance by toxin-producing taxa (Anderson et al. 2002; Heisler et

229 al. 2008; Dolman et al. 2012; Scott et al. 2013) or clones (Kardinaal et al. 2007; Touzet et al.

230 2007)_ENREF_25_ENREF_12 and if nutrient limitation promotes the internal accumulation of toxic

231 molecules, as shown in our analysis. These insights also provide a means for anticipating which

232 toxins will be triggered as a function of $\mathrm{N}$ - or P-limitation during bloom termination. Thus, the

233 stoichiometric relationships we have uncovered may provide a practical basis for better

234 forecasting the potential occurrence of toxic compounds in the aquatic environment, possibly

235 allowing the creation of an "early warning system" for more detailed chemical analyses of

236 suspended particulate matter, both in drinking water supplies and in surface waters that support

237 fisheries and heavy recreational use.

Our analysis demonstrates that the production of stoichiometrically distinct toxins can be explained, at least partially, by the availabilities of key limiting nutrients in the environment and within the cell. However, we note that the production of toxins may also be affected by other

241 environmental factors. In particular, C-rich toxins may be sensitive to changes in $\mathrm{CO}_{2}$ and light 242 availability, as these resources provide phytoplankton with $\mathrm{C}$ and energy. Indeed, enhanced $\mathrm{CO}_{2}$ 243 availabilities have been shown to increase the production of C-rich toxins such as domoic acid 244 (Sun et al. 2011) and karlotoxin (Fu et al. 2010), particularly under P-limited conditions.

245 However, there seems no general response of C-rich toxins to increasing light intensities. More 246 specifically, increasing light intensities were shown to cause an increase (Bates 1998; Cusack et 
al. 2002) or a decrease (Auro \& Cochlan 2013) in the production of domoic acid, while the sensitivity of hemolytic activity (Baker et al. 2007; Granéli et al. 2012) and DSP toxins (Nielsen et al. 2013) to light intensity seems to be marginal or even absent. Enhanced light intensities were shown to cause an increase in the production of the N-rich PSP toxins (Parkhill \& Cembella 1999; Etheridge \& Roesler 2005) and microcystins (Wiedner et al. 2003; Tonk et al. 2005) at limiting light levels, but caused a decrease at saturating light levels. Generally, the response of $\mathrm{N}$ - and C-rich toxins to light availability seems less pronounced as compared to nutrient limitation, while enhanced $\mathrm{CO}_{2}$ availabilities may further promote the production of C-rich toxins under nutrient limiting conditions.

Our results provide a broad picture of how the synthesis of toxins in response to nutrient limitation might be modified by internal allocation processes that shunt excess $\mathrm{C}$ and nutrients not to toxins but towards storage compounds, as in the case of $\mathrm{N}$ in cyanobacteria. In higher plants, nutrient limitation may result in a surplus of fixed $\mathrm{C}$ as well, which can also be allocated either to storage compounds or to C-rich secondary metabolites (Koricheva et al. 1998).

Likewise, the availability of $\mathrm{C}$ and nutrients has been shown to affect synthesis of $\mathrm{C}$ - or N-rich secondary metabolites in bacteria and fungi (Sanchez \& Demain 2002; Cornforth \& Foster 2013). Even though secondary metabolites are highly diverse in function among producers, the synthesis of these molecules generally has a flexible component that at least partially depends on the interplay between their own elemental composition and the relative availability of key resources. Thus, toxin production can be expected to behave in broadly predictable ways across a wide variety of biota.

Ongoing anthropogenic loading of nutrients will lead to deterioration of water quality not only by promoting biomass accumulation of phytoplankton, but by affecting both the quantities 
270 and the biochemical composition of the toxins they can produce, especially when nutrient

271 loading leads to strong stoichiometric imbalances of $\mathrm{N}$ and $\mathrm{P}$. For instance, nutrient inputs from

272 nonpoint sources such as atmospheric $\mathrm{N}$ deposition or release of sediment-bound $\mathrm{P}$ (Carpenter et

273 al. 1998; Elser et al. 2009) may shift phytoplankton from N- to P-limitation, or vice versa, and

274 thereby alter their toxicity. Thus, application of stoichiometric theory, together with knowledge

275 of the phytoplankton species and the stoichiometric composition of the toxins they produce, may 276 help us predict whether nutrient loading will cause an increase, decrease, or no change in overall

277 toxicity in natural waters (Anderson et al. 2002; Heisler et al. 2008), with important potential 278 consequences for the various services provided by freshwater and marine ecosystems. 


\section{Acknowledgements}

281 We thank the editor and anonymous referees for their valuable comments on the manuscript.

282 This work was supported in part by the NSF grants DMS-0342239 to VHS and DEB-0950179 to 283 JJE. 


\section{References}

Allen, M.M. (1984). Cyanobacterial cell inclusions. Annu. Rev. Microbiol., 38, 1-25.

Anderson, D.M., Glibert, P.M. \& Burkholder, J.M. (2002). Harmful algal blooms and eutrophication: Nutrient sources, composition, and consequences. Estuaries, 25, 704-726.

Auro, M.E. \& Cochlan, W.P. (2013). Nitrogen utilization and toxin production by two diatoms of the Pseudo-nitzschia pseudodelicatissima Complex: P. cuspidata and P. fryxelliana. J. Phycol., 49, 156-169.

Baker, J.W., Grover, J.P., Brooks, B.W., Urena-Boeck, F., Roelke, D.L., Errera, R. et al. (2007). Growth and toxicity of Prymnesium parvum (Haptophyta) as a function of salinity, light, and temperature. J. Phycol., 43, 219-227.

Bates, S.S. (1998). Ecophysiology and Metabolism of ASP Toxin Production. In: Physiological ecology of harmful algal blooms (eds. Anderson, DM, Cembella, AD \& Hallegraeff, GM). Springer-Verlag Berlin Heidelberg Heidelberg, Germany, pp. 405-426.

Borenstein, M., Hedges, L.V., Higgins, J.P.T. \& Rothstein, H.R. (2009). Introduction to MetaAnalysis. John Wiley \& Sons, Chichester, UK.

Carpenter, S.R., Caraco, N.F., Correll, D.L., Howarth, R.W., Sharpley, A.N. \& Smith, V.H. (1998). Nonpoint pollution of surface waters with phosphorus and nitrogen. Ecol. Appl., $8,559-568$.

Cembella, A.D. (1998). Ecophysiology and Metabolism of Paralytic Shellfixh Toxins in Marine Microalgae. In: Physiological Ecology of Harmful Algal Blooms (eds. Anderson, DM, Cembella, AD \& Hallegraeff, GM). Springer-Verlag Berlin Heidelberg Heidelberg, Germany, pp. 281-403. 
Cornforth, D.M. \& Foster, K.R. (2013). Competition sensing: The social side of bacterial stress responses. Nature Reviews Microbiology, 11, 285-293.

Cusack, C.K., Bates, S.S., Quilliam, M.A., Patching, J.W. \& Raine, R. (2002). Confirmation of domoic acid production by Pseudo-nitzschia australis (Bacillariophyceae) isolated from Irish waters. Journal of Phycology, 38, 1106-1112.

Dolman, A.M., Rucker, J., Pick, F.R., Fastner, J., Rohrlack, T., Mischke, U. et al. (2012). Cyanobacteria and cyanotoxins: The influence of nitrogen versus phosphorus. PLoS ONE, 7.

Edvardsen, B. \& Imai, I. (2006). The Ecology of Harmful Flagellates within Prymnesiophyceae and Raphidophyceae. In: Ecology of Harmful Algae (eds. Granéli, E \& Turner, JT). Springer-Verlag Berlin Heidelberg Heidelberg, Germany, pp. 67-79.

Elser, J.J., Andersen, T., Baron, J.S., Bergstrom, A.K., Jansson, M., Kyle, M. et al. (2009). Shifts in lake N:P stoichiometry and nutrient limitation driven by atmospheric nitrogen deposition. Science, 326, 835-837.

Elser, J.J., Bracken, M.E.S., Cleland, E.E., Gruner, D.S., Harpole, W.S., Hillebrand, H. et al. (2007). Global analysis of nitrogen and phosphorus limitation of primary producers in freshwater, marine and terrestrial ecosystems. Ecol. Lett., 10, 1135-1142.

Etheridge, S.M. \& Roesler, C.S. (2005). Effects of temperature, irradiance, and salinity on photosynthesis, growth rates, total toxicity, and toxin composition for Alexandrium fundyense isolates from the Gulf of Maine and Bay of Fundy. Deep Sea Res. (II Top. Stud. Oceanogr.), 52, 2491-2500. 
Fu, F.X., Place, A.R., Garcia, N.S. \& Hutchins, D.A. (2010). $\mathrm{CO}_{2}$ and phosphate availability control the toxicity of the harmful bloom dinoflagellate Karlodinium veneficum. Aquat. Microb. Ecol., 59, 55-65.

Glibert, P.M. \& Burkholder, J.M. (2011). Harmful algal blooms and eutrophication: "Strategies" for nutrient uptake and growth outside the Redfield comfort zone. Chin. J. Oceanol. Limnol., 29, 724-738.

Granéli, E., Edvardsen, B., Roelke, D.L. \& Hagstrom, J.A. (2012). The ecophysiology and bloom dynamics of Prymnesium spp. Harmful Algae, 14, 260-270.

Granéli, E. \& Flynn, K. (2006). Chemical and Physical Factors Influencing Toxin Content. In: Ecology of Harmful Algae (eds. Granéli, E \& Turner, JT). Springer-Verlag Berlin Heidelberg Heidelberg, pp. 229-241.

Granéli, E., Johansson, N. \& Panosso, R. (1998). Cellular Toxin Contents in Relation to Nutrient Conditions for Different Groups of Phytotoxins. In: Harmful Algae (eds. Reguera, B, Blanco, J, Fernández, ML \& Wyatt, T). Xunta de Galicia and IOC-UNESCO Santiago de Compostella, pp. 321-324.

Granéli, E. \& Turner, J.T. (2006). Ecology of Harmful Algae. Springer-Verlag Berlin Heidelberg, Heidelberg, Germany.

Hackett, J.D., Wisecaver, J.H., Brosnahan, M.L., Kulis, D.M., Anderson, D.M., Bhattacharya, D. et al. (2013). Evolution of Saxitoxin Synthesis in Cyanobacteria and Dinoflagellates. Mol. Biol. Evol., 30, 70-78.

Heisler, J., Glibert, P.M., Burkholder, J.M., Anderson, D.M., Cochlan, W., Dennison, W.C. et al. (2008). Eutrophication and harmful algal blooms: A scientific consensus. Harmful Algae, 8, 3-13. 
Hillebrand, H., Steinert, G., Boersma, M., Malzahn, A., Meunier, C.L., Plum, C. et al. (2013). Golman revisited: Faster-growing phytoplankton has lower N:P and lower stoichiometric flexibility. Limnol. Oceanogr., 58, 2076-2088.

Iason, G.R., Dicke, M. \& Hartley, S.E. (2013). The Ecology of Plant Secondary Metabolites: From Genes to Global Processes. Cambridge University Press, New York.

Kardinaal, W.E.A., Janse, I., Kamst-van Agterveld, M., Meima, M., Snoek, J., Mur, L.R. et al. (2007). Microcystis genotype succession in relation to microcystin concentrations in freshwater lakes. Aquat. Microb. Ecol., 48, 1-12.

Keller, L. \& Surette, M.G. (2006). Communication in bacteria: An ecological and evolutionary perspective. Nature Reviews Microbiology, 4, 249-258.

Klausmeier, C.A., Litchman, E., Daufresne, T. \& Levin, S.A. (2004). Optimal nitrogen-tophosphorus stoichiometry of phytoplankton. Nature, 429, 171-174.

Koricheva, J., Larsson, S., Haukioja, E. \& Keinanen, M. (1998). Regulation of woody plant secondary metabolism by resource availability: Hypothesis testing by means of metaanalysis. Oikos, 83, 212-226.

Legrand, C., Johansson, N., Johnsen, G., Borsheim, K.Y. \& Graneli, E. (2001). Phagotrophy and toxicity variation in the mixotrophic Prymnesium patelliferum (Haptophyceae). Limnol. Oceanogr., 46, 1208-1214.

Moustafa, A., Loram, J.E., Hackett, J.D., Anderson, D.M., Plumley, F.G. \& Bhattacharya, D. (2009). Origin of saxitoxin biosynthetic genes in cyanobacteria. PLoS ONE, 4.

Nielsen, L.T., Krock, B. \& Hansen, P.J. (2013). Production and excretion of okadaic acid, pectenotoxin-2 and a novel dinophysistoxin from the DSP-causing marine dinoflagellate 
Dinophysis acuta: Effects of light, food availability and growth phase. Harmful Algae, 23, 34-45.

Orihel, D.M., Bird, D.F., Brylinsky, M., Chen, H.R., Donald, D.B., Huang, D.Y. et al. (2012). High microcystin concentrations occur only at low nitrogen-to-phosphorus ratios in nutrient-rich Canadian lakes. Can. J. Fish. Aquat. Sci., 69, 1457-1462.

Parkhill, J.P. \& Cembella, A.D. (1999). Effects of salinity, light and inorganic nitrogen on growth and toxigenicity of the marine dinoflagellate Alexandrium tamarense from northeastern Canada. J. Plankton Res., 21, 939-955.

Quigg, A., Finkel, Z.V., Irwin, A.J., Rosenthal, Y., Ho, T.Y., Reinfelder, J.R. et al. (2003). The evolutionary inheritance of elemental stoichiometry in marine phytoplankton. Nature, 425, 291-294.

Sanchez, S. \& Demain, A.L. (2002). Metabolic regulation of fermentation processes. Enzyme Microb. Technol., 31, 895-906.

Scott, J.T., McCarthy, M.J., Otten, T.G., Steffen, M.M., Baker, B.C., Grantz, E.M. et al. (2013). Comment: An alternative interpretation of the relationship between TN:TP and microcystins in Canadian lakes. Can. J. Fish. Aquat. Sci., 70, 1265-1268.

Sivonen, K. \& Jones, G. (1999). Cyanobacterial Toxins. In: Toxic Cyanobacteria in Water: A Guide to their Public Health Consequences, Monitoring and Management (eds. I., C \& J., B). E \& FN Spon, WHO London, pp. 41-112.

Skovgaard, A., Legrand, C., Hansen, P.J. \& Graneli, E. (2003). Effects of nutrient limitation on food uptake in the toxic haptophyte Prymnesium parvum. Aquat. Microb. Ecol., 31, 259265. 
Smalley, G.W., Coats, D.W. \& Stoecker, D.K. (2003). Feeding in the mixotrophic dinoflagellate Ceratium furca is influenced by intracellular nutrient concentrations. Mar. Ecol. Prog. Ser., 262, 137-151.

Smith, V.H. (2003). Eutrophication of freshwater and coastal marine ecosystems: A global problem. Environ. Sci. Pollut. Res., 10, 126-139.

Staunton, J. \& Weissman, K.J. (2001). Polyketide biosynthesis: A millennium review. Natural Product Reports, 18, 380-416.

Sterner, R.W. \& Elser, J.J. (2002). Ecological Stoichiometry: The Biology of Elements from Molecules to the Biosphere. Princeton University Press, Princeton.

Stoecker, D.K., Tillmann, U. \& Granéli, E. (2006). Phagotrophy in Harmful Algae. In: Ecology of Harmful Algae (eds. Granéli, E \& Turner, JT). Springer-Verlag Berlin Heidelberg Heidelberg, Germany, pp. 177-187.

Sun, J., Hutchins, D.A., Feng, Y.Y., Seubert, E.L., Caron, D.A. \& Fu, F.X. (2011). Effects of changing $\mathrm{pCO}_{2}$ and phosphate availability on domoic acid production and physiology of the marine harmful bloom diatom Pseudo-nitzschia multiseries. Limnol. Oceanogr., 56, 829-840.

Tillmann, U. (2003). Kill and eat your predator: A winning strategy of the planktonic flagellate Prymnesium parvum. Aquat. Microb. Ecol., 32, 73-84.

Tonk, L., Visser, P.M., Christiansen, G., Dittmann, E., Snelder, E., Wiedner, C. et al. (2005). The microcystin composition of the cyanobacterium Planktothrix agardhii changes toward a more toxic variant with increasing light intensity. Appl. Environ. Microbiol., 71, $5177-5181$. 
416 Touzet, N., Franco, J.M. \& Raine, R. (2007). Characterization of nontoxic and toxin-producing strains of Alexandrium minutum (Dinophyceae) in Irish coastal waters. Appl. Environ. Microbiol., 73, 3333-3342.

419 Van de Waal, D.B., Verspagen, J.M.H., Lurling, M., Van Donk, E., Visser, P.M. \& Huisman, J. (2009). The ecological stoichiometry of toxins produced by harmful cyanobacteria: An experimental test of the carbon-nutrient balance hypothesis. Ecol. Lett., 12, 1326-1335.

Wiedner, C., Visser, P.M., Fastner, J., Metcalf, J.S., Codd, G.A. \& Mur, L.R. (2003). Effects of light on the microcystin content of Microcystis strain PCC 7806. Appl. Environ.

424 Microbiol., 69, 1475-1481.

425

426 


\section{Supporting Information}

428 The following Supporting Information is available for this article:

429

430

431 nutrient-sufficient conditions.

Figure S1. Overview of investigated datasets grouped according to toxin stoichiometry, type of experimental nutrient limitation, habitat of origin, identity of toxin or toxin group, and taxonomic group (species or genus). Numbers between parentheses indicate for each category the number of datasets that were available for analysis.

Table S1. Toxin quota and toxicities of various phytoplankton species grown under low N, low $\mathrm{P}$ and nutrient-sufficient conditions.

Table S2. C:N:P stoichiometry of various phytoplankton species grown under low N, low P and 
440 Table 1. Overview of toxins grouped according to their $\mathrm{C}: \mathrm{N}$ ratio.

\begin{tabular}{|c|c|c|c|c|}
\hline Group & Toxins & & Molecular formula & $\begin{array}{l}\mathrm{C}: \mathrm{N} \\
\text { ratio* }^{*}\end{array}$ \\
\hline \multirow[t]{4}{*}{ N-rich } & PSP & Paralytic Shellfish Poisoning toxins (incl. saxitoxin, STX) & $\mathrm{C}_{10} \mathrm{H}_{19} \mathrm{~N}_{7} \mathrm{O}_{4}$ & 1.5 \\
\hline & $\mathrm{MC}$ & Microcystin (incl. microcystin-LR; microcystin-RR) & $\begin{array}{l}\mathrm{C}_{49} \mathrm{H}_{74} \mathrm{~N}_{10} \mathrm{O}_{12} \text { (MC-LR); } \\
\mathrm{C}_{49} \mathrm{H}_{75} \mathrm{~N}_{13} \mathrm{O}_{12} \text { (MC-RR) }\end{array}$ & 4.3 \\
\hline & CYN & Cylindrospermopsin & $\mathrm{C}_{15} \mathrm{H}_{21} \mathrm{~N}_{5} \mathrm{O}_{7} \mathrm{~S}$ & 3.0 \\
\hline & NOD & Nodularin & $\mathrm{C}_{41} \mathrm{H}_{60} \mathrm{~N}_{8} \mathrm{O}_{10}$ & 5.1 \\
\hline \multirow[t]{12}{*}{ C-rich } & ANTX & Anatoxin a & $\mathrm{C}_{10} \mathrm{H}_{15} \mathrm{NO}$ & 10 \\
\hline & ASP & Amnesic Shellfish Poisoning toxin (incl. domoic acid, DA) & $\mathrm{C}_{15} \mathrm{H}_{21} \mathrm{NO}_{6}$ & 15 \\
\hline & GYM & Gymnodimine & $\mathrm{C}_{32} \mathrm{H}_{45} \mathrm{NO}_{4}$ & 32 \\
\hline & SPX & Spirolide & $\mathrm{C}_{42} \mathrm{H}_{61} \mathrm{NO}_{7}$ & 42 \\
\hline & PLTX & Palytoxin & $\mathrm{C}_{129} \mathrm{H}_{223} \mathrm{~N}_{3} \mathrm{O}_{54}$ & 43 \\
\hline & OVTX & Ovatoxin (incl. OVTX-a) & $\mathrm{C}_{129} \mathrm{H}_{223} \mathrm{~N}_{3} \mathrm{O}_{52}$ & 43 \\
\hline & DSP & $\begin{array}{l}\text { Diarrheic Shellfish Poisoning toxins (incl. okadaic acid, OA; } \\
\text { dinophysis toxins, DTX-1, DTX-2) }\end{array}$ & $\begin{array}{l}\mathrm{C}_{44} \mathrm{H}_{68} \mathrm{O}_{13}(\mathrm{OA}, \mathrm{DTX}-2) \\
\mathrm{C}_{45} \mathrm{H}_{70} \mathrm{O}_{13} \text { (DTX-1); }\end{array}$ & - \\
\hline & NSP & Neurotoxic Shellfish Poisoning toxin (incl. brevetoxin, $\mathrm{PbTx}$ ) & $\mathrm{C}_{49} \mathrm{H}_{70} \mathrm{O}_{13}$ & - \\
\hline & KMTX & Karlotoxins (incl. KMTX-1-1, KMTX-2) & $\begin{array}{l}\mathrm{C}_{67} \mathrm{H}_{120} \mathrm{O}_{24}(\text { KMTX-1-1); } \\
\mathrm{C}_{67} \mathrm{H}_{121} \mathrm{ClO}_{24}(\text { KMTX-2) }\end{array}$ & - \\
\hline & CTX & Ciguatoxin & $\mathrm{C}_{61} \mathrm{H}_{88} \mathrm{O}_{19}$ & - \\
\hline & MTX & Maitotoxin & $\mathrm{C}_{164} \mathrm{H}_{256} \mathrm{O}_{68} \mathrm{~S}_{2} \mathrm{Na}_{2}$ & - \\
\hline & HA & Hemolytic activity based on bioassays & & \\
\hline
\end{tabular}

441 "Values refer to the described toxins, or to the average of the shown analogues. 
443 Table 2. Results of one-sample t-tests comparing relative changes in N-and C-rich toxin quotas

444 or toxicities between a treatment and its control, with sample size $(n)$, mean change, $95 \%$

445 confidence interval, and $P$-value at a significance level of 0.05 (indicated in bold).

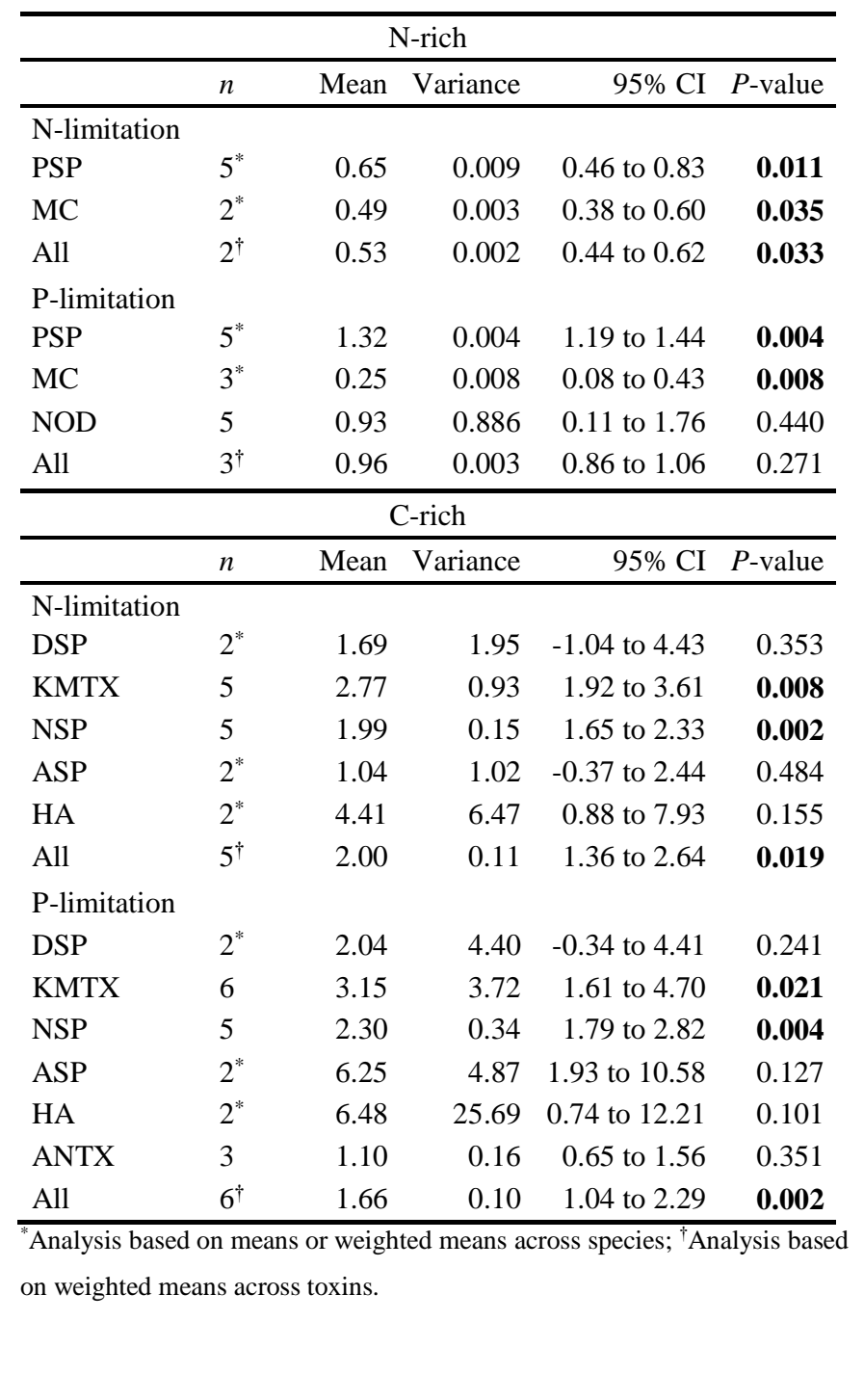




\section{Figure legends}

451 Fig. 1. Relative changes of N-rich toxins in response to nutrient limitation. (a) N-limitation and (b) P-limitation. White symbols show weighted means for individual toxins with error bars

453 indicating SE across means of species; grey symbols show the overall weighted means of N-rich 454 toxins with error bars indicating SE across means of toxins. The horizontal line indicates absence 455 of response. Asterisks indicate significances $P<0.01(* *)$ and $P<0.05(*)$.

Fig. 2. Relative changes of C-rich toxins in response to nutrient limitation. (a) N-limitation and (b) P-limitation. White symbols show weighted means for individual toxins with error bars indicating SE across means of species; grey symbols show the overall weighted means of C-rich 460 toxins with error bars indicating SE across means of toxins. The horizontal line indicates absence 461 of response. Asterisks indicate significances $P<0.01(* *)$ and $P<0.05(*)$.

Fig. 3. Relative changes of N- and C-rich toxins in response to cellular N:P ratios. (a) N-rich 464 toxins and (b) C-rich toxins. Symbols show weighted means for individual toxins with error bars 465 indicating SE across means of species. The horizontal line indicates an absence of response, and 466 the vertical line illustrates the Redfield N:P ratio $(\mathrm{N}: \mathrm{P}=16)$. The solid grey line in $(\mathbf{a})$ shows the 467 linear fit to all data $\left(\mathrm{R}^{2}=0.989, n=6, P<0.001\right)$. 